\title{
Myocardial Revascularization without Extracorporeal Circulation
}

The myocardial revascularization without extracorporeal circulation (ECC) is not new, and the first reports of consecutive series date back from the beginning of the 80 's ${ }^{1-5}$.

Due to the comfort of performing saphenous-coronary anastomoses in cardioplegia, cardiovascular surgeons did not accept this alternative initially, even considering that the coronary approach is achieved on the heart surface, which would not require cardiac arrest in extracorporeal circulation.

After a long period of skepticism, there was an extraordinary and increasing interest in the mid-90's for this revascularization alternative, with the appearance of the "minimal invasion" concepts".

The man points for such acceptance to occur were the introduction of stabilizers, the recognition of less morbidity and mortality, especially for high-risk patients, and the consistent results observed in the original series.

With the increase of experience in other centers, it was observed that the myocardial revascularization could be complete and show superior results when compared to the conventional technique.

In the registry of the Society of Thoracic Surgeons (STS), the revascularization without ECC (off-pump) offers better results than the conventional technique regarding mortality and morbidity, and these data have been confirmed in other literature studies ${ }^{7-10}$.

If the differences are not significant for low-risk patients, the difference in post-operative complications is noteworthy for those with important co-morbidities.

Among other advantages, it is worth mentioning the possibility of extubation in the operating room, shorter Intensive Care Unit (ICU) and hospital stay, decreased need for blood transfusion and advantages regarding hospital costs.

Among the debatable points it is worth mentioning the decrease of the inflammatory response, of apoptosis, and the quality of the anastomoses.

The preferential candidates to revascularization without ECC are elderly patients with previous stroke; chronic obstructive pulmonary disease; chronic renal failure; carotid pathology; poor ventricular function; and aorta calcification ${ }^{12-14}$.

Initially, the technique was used solely for anterior descending coronary, right coronary and diagonal coronary lesions, but exposing the marginals with Lima stitches and the introduction of suction (Octopus ${ }^{\circledR}$ ) or compression stabilizers (Guidant ${ }^{\circledR}$ - Millennium $\AA$ ), associated to a heart positioner (Starfish $®$ ) increased the indications and possibilities of revascularization without ECC.

The applicability has varied along the years, from sporadic indications to $100 \%$ for different surgical groups.

During 23 years of our experience, out total applicability was $21 \%$ in 3,727 cases, reaching $49 \%$ in the last five years.

The variations found in literature can be attributed to the surgeon's determination and training in the technique, to the concept of functional more than anatomical revascularization, and the demography of patients referred to surgery.

Nevertheless, there is no doubt that the anastomoses performed with the heart beating is not an indication for all patients, and much less for all surgeons. Only experience and training can assign the patients to either technique.

Finally, the revascularization without ECC, the use of arterial grafts and the surgical ventricular remodeling in ischemic cardiomyopathy are considered some of the greatest contributions of surgery to the treatment of coronary affections, and the comparisons of the medical percutaneous treatment with the surgical approach must be reconsidered in the light of such contributions. 


\section{REFERENCES}

1. Buffolo E, Andrade JCS, Succi JE et al. Revascularização direta do miocárdio sem circulação extracorpórea. Descrição da técnica e resultados iniciais. Arq Bras Cardiol 1982; 38: 365-373.

2. Benetti FJ. Direct coronary surgery with saphenous vein bypass without either cardiopulmonary bypass or cardiac arrest. J Cardiovasc Surg 1985; 26: 217-22.

3. Buffolo E, Andrade JCS, Branco JNR et al. Myocardial revascularization without extracorporeal circulation. Seven-years experience in 593 cases. Eur J Cardiothorac Surg 1990; 4: 504-7.

4. Buffolo E, Andrade JCS, Branco JNR et al. Coronary artery bypass without cardiopulmonary bypass. Ann Thorac Surg 1996; 61: 636.

5. Rivetti LA, Gandra SMA, Initial experience using an intraluminal shunt during revascularization of the beating heart. Ann Thorac Surg 1997; 63: 1742-47.

6. Calafiore AM, Gianmarco GD, Teodori G et al. Left anterior descending coronary artery grafting via left anterior small thoracotomy without cardiopulmonary bypass. Ann Thorac Surg 1996; $61: 1658-65$

7. Jasinski MJ, Wos S, Olszowka P et al. Dysfunction of left ventricle as an indication for off-pump coronary artery bypass grafting. Heart Surg Forum 2003; 6(6): E85-8.

8. Van Dijk D, Nierich AP, Jansen EW et al. Early outcome after off-pump versus on-pump coronary bypass surgery: results from a randomized study. Circulation 2001; 104: 1761-66.
9. Angelini GD, Taylor FC, Reeves BC et al. Early and midterm outcome after off-pump and on-pump surgery in a beating heart against cardioplegic arrest studies (BHACAS 1 and 2): a pooled analysis of two randomizes controlled trials. Lancet 2002; 359: 1194-9.

10. Cleveland JC, Shroyer ALW, Chen AY et al. Off-pump coronary artery bypass grafting decrease risk-adjusted mortality and morbidity. Ann Thorac Surg 2001; 72: 1282-9.

11. Gerola LR, Buffolo E, Jasbik W et al. Off-pump versus on-pump myocardial revascularization in low-risk patients with one or two vessel disease: Perioperative results in a multicenter randomized controlled trial. Ann Thorac Surg 2004; 77: 569-73.

12. Kilo J, Baumer H, Czerny M et al. Target vessel revascularization without cardiopulmonary bypass in elderly high-risk patients. Ann Thorac Surg 2001; 71: 537-42.

13. Kshettry VR, Flavin TF, Emery RW et al. Does multivessel off-pump coronary artery bypass reduce postoperative morbidity. Ann Thorac Surg 2000; 69: 1725-30.

14. Al-Ruzzeh S, Nakamura K, Athanasiou T et al. Does off-pump coronary artery bypass (OPCAB) surgery improve the outcome in high-risk patients?: a comparative study of 1,398 high-risk patients. Eur J Cardiothorac Surg 2003; 23(1): 50-5.

15. Lima RC. Padronização técnica da revascularização do miocárdio da artéria circunflexa e seus ramos sem circulação extracorpórea. Tese de Doutorado. São Paulo - Universidade Federal de São Paulo/Escola Paulista de Medicina. 